\title{
Language learning and teaching - theory and practice
}

\section{Theory and principles}

90-1 Bresson, Daniel (U. of Aix-Marseille I). Langue, linguistique et grammaire. Mauvaises querelles et vrais problèmes. [Language, linguistics and grammar. Serious disagreements and real problems.] Langues Modernes (Paris), 83, 3/4 (1989), 21-8

Linguistics has emerged as a discipline in its own right during recent years and has encountered some hostility, not always unjustified, from teachers of languages. Teaching and learning are not strictly speaking the concern of linguistics but, it is claimed, more properly of psycholinguistics. Nevertheless linguistics has a contribution to make both in analysing the structures of the language and in providing correct, comprehensible and usable descriptions of it.

Explicit teaching of grammar will retain its place as long as languages continue to be taught for only a few hours a week in large groups. Grammar should, however, be presented within a communicative context.

\section{0-2 Cazden, Courtney B. (Harvard U.). Contributions of the Bakhtin Circle to 'communicative competence'. Applied Linguistics (Oxford), 10, 2 (1989), 116-27.}

Soviet scholar Mikhail Bakhtin's writings were not available in English in 1966, when Dell Hymes first wrote about communicative competence. Yet there are important similarities in their ideas: their explicit opposition to the Saussurian dichotomy between langue and parole; their belief that speech is both structured and emergent; their research on literature as well as language; and their conceptions of language acquisition.

Differences can be separated into themes emphasised by each scholar. Hymes draws on a much greater base of sociolinguistic research; and he frequently writes about linguists' responsibility to work for change, especially in education. Bakhtin analysed the intrinsic intertextuality of all utterances, and the consequences of 'heteroglossia' for speakers and writers-notably, intra-personal conflicts during the process of expression because of the 'auras' that accrue to language forms from awareness of their previous contextualised use. (Examples of such conflicts include an account of one black teacher's struggles, in a one-year university master's program, with the academic writing expected by his professors)

\section{0-3 Connors, Kathleen ( $U$. of Montreal). The distinction between L2 learning and acquisition. Bulletin of the CAAL (Montreal, Canada), 11, 1 (1989), 39-48.}

This article deals with the reasons for distinguishing learning from acquisition which have, in recent years, been the subject of debate in the study of speakers attempting to assimilate a second language. It looks at the kinds of studies which have and have not appeared to distinguish acquirers clearly from learners, and the kinds of language acquisition of learning processes which do and do not seem clearly to differentiate them. The entire problem is inseparable from that of understanding the differences between L1 and L2 acquisition and the empirical research on certain aspects of the acquisition of English, the results of which began to be known mainly in the 1970s. Certain fragmentary results of studies on the learning and acquisition of French in more recent years indicate that the distinction in question is indeed of theoretical importance, though the results of the two postulated processes may be impossible to disentangle with certainty in concrete cases for L2 speakers.

\section{0-4 Davies, Alan (U. of Edinburgh). Communicative competence as language use. Applied Linguistics (Oxford), 10, 2 (1989), 157-70.}

At the heart of the communicative competence model put forward by Hymes (1971) is, it is argued, a systematic ambiguity in that it appears to mean both the decontextualised, displaced language ability associated with the views of Bernstein (elaborated code), Donaldson (decentration), Wells (hypoth- eses), and Cummins (CALP), and the interpersonal, socialising, context-dependent language ability associated with the views of (again) Bernstein (restricted code), (again) Cummins (BICS), Frake (asking rituals), etc. What has become clear is that such dichotomies are untenable and that either they 
hide a divisive political construct (for example, that communicative competence means an élite code) or they argue for the addition of one or more domains, for example, writing, or simply for the role of language in education. Communicative competence was presented as an explanatory framework for failure. It did not explain, it may have described. The paper argues for a view of communicative competence as language use, a lesser but more readily achievable ambition, achievable both in theory and in pedagogy.

\section{0-5 Dubin, Fraida (U. of Southern California). Situating literacy within traditions of communicative competence. Applied Linguistics (Oxford) 10, 2 (1989), 171-81.}

This paper investigates some of the affinities between the traditions of communicative competence and literacy studies by tracking back 25 years to the early calls for an ethnography of communication. In this decade, literacy studies have utilised ethnographic methodology, keeping the tradition alive and flourishing.

The paper also shows how communicative competence theory, in more recent times, has branched into a communicative approach to secondlanguage pedagogy. In doing so, the tradition has mingled both 'psycho-' and 'socio-' views of language. Looking into the ways scholars have characterised literacy as a field, particularly through 'autonomous' and 'ideological' models, offers a window for viewing similar strands in applied linguistics.

\section{0-6 Galisson, Robert (U. de la Sorbonne nouvelle-Paris-III). Problématique de} l'autonomie en didactique des langues (contexte français). [Problems concerning autonomy in language teaching (in the French context.)] Bulletin of the CAAL (Montreal, Canada), 10, 2 (1988), 29-47.

The teaching and learning of languages has never developed as fast and as much as it has since the Second World War. For this reason, educationists ponder over the future of their discipline. Since there are more and more people who support autonomy, the author tries to sum up the problems that it presents. His research work centres around three principal sources of information: the dis- cipline's successive titles; its relations with so-called reference disciplines; and its claims to being scientific. The results of this investigation lead him (1) to conclude that there is no alternative to autonomy for language teaching and learning; and (2) to militate in favour of a federalism that is as broad as possible, and for a 'general didactics of languages and cultures'.

\section{0-7 Richards, Keith and Skelton, John (Aston U., Birmingham). Nodes and networks: choosing for real. Applied Linguistics (Oxford), 10, 2 (1989), 231-43.}

This paper examines certain aspects of the communicative approach which give cause for concern and suggests a way of coming to terms with some of the problems raised. It argues that 'manifesto thinking' has meant that fundamental problems have been swept under the carpet and local opportunity has been sacrificed to correct form. An examination of classroom data from a formal grammar lesson indicates that the potential of the accidental moment in student/teacher interaction is considerable. In order to exploit this, what is needed is a fresh perspective on language teaching rather than a new 'movement' or 'approach'. Connectionist models of cognitive processes provide a powerful metaphor for such a standpoint. A consideration of central features of the connectionist position indicates how attention might be shifted to choice points, or 'nodes', within a network of linguistic and pedagogic opportunity in the language classroom.

\section{0-8 Spolsky, Bernard (Bar-llan U., Israel). Communicative competence.} language proficiency, and beyond. Applied Linguistics (Oxford), 10, 2 (1989), $138-56$.

The development of a theory of communicative competence was one reaction to Chomsky's somewhat limiting definition of the scope of linguistic theory. Communicative competence, as Hymes proposed it, seemed a particularly relevant idea to those interested in second language learning. The relevance of a theory of communicative competence to language testing was first noted by Cooper (1968) 
and explored by Canale and Swain (1980). Language tests involve measuring a subject's knowledge of, and proficiency in, the use of a language. Communicative competence is a theory of the nature of such knowledge and proficiency. But the formalisation of the theory remains a problem. A preference model appears to be a useful way to characterise communicative competence; it has many advantages over competing models. But it, too, is now challenged by the promise of models within the theory of Parallel Distributed Processing

\section{0-9 Stalker, James C. (Michigan State U.). Communicative competence,} pragmatic functions, and accommodation. Applied Linguistics (Oxford), 10, 2 (1989). 182-93.

Communicative competence is that part of our language knowledge which enables us to choose the communicative system we wish to use, and, when that selected system is language, to connect the goals and contexts of the situation with the structures which we have available in our linguistic repertoire through functional choices at the pragmatic level. In making these selections, language users accommodate linguistic features both consciously and unconsciously in order to adjust the social distance between the producer and the receiver. When the goal is to communicate with a stranger, to engage in public discourse, the most probable functional selection is to choose linguistic features which mark one's discourse as being acceptable for public discourse, to choose standard English. In part, the feature selection will be unconscious, but to some extent it will be conscious, and will rely on those norms which are publicly discussed, features which incorporate regional and social distinctions as well as notions of correctness and acceptability. Because the selection and use of standard English involves a high level of metalinguistic awareness, it might best be characterised as a communicative level phenomenon rather than a feature or structural level one.

90-10 Widdowson. Henry G. (U. of London). Authority and autonomy in second language teaching. Bulletin of the CAAL (Montreal, Canada), 10, 2 (1988), 7-14.

For the profession of language pedagogy to remain dynamic and alert to new possibilities of development it needs to be stimulated. But the stimulation needs to be controlled in some way so that its effects are tempered and made beneficial to local situations. Ideas, no matter how stimulating or authoritative, have to be referred to the conditions of particular cultural and eductional settings if they are to be effective, and these settings define the autonomous role of pedagogy. These questions of authority and autonomy and the relationship between global ideas and local beliefs and values are illustrated by literary examples. It is suggested that such fictional representation can be just as effective as factual research in raising awareness and stimulating discussion of these issues.

\section{0-11 Widdowson, H. G. (U. of London). Knowledge of language and ability for use. Applied Linguistics (Oxford), 10, 2 (1989), 128-37.}

This paper seeks to clarify the notion of competence in language and to draw on its relevance to language teaching practices. It is suggested that Hymes's account of communicative competence as incorporating language beyond grammar and ability as well as knowledge raises problematic issues concerning the analysability and accessibility of knowledge and the scope and application of linguistic rules. A consideration of these issues suggests the possibility that competence for use may involve not so much the generation of expressions by direct reference to rules as the adjustment of pre-assembled and memorised patterns. The ability to use language, therefore, may have to do with access which is relatively independent of the analytic knowledge of grammar as defined in Chomsky's original concept of competence.

\section{0-12 Zuber-Skerritt, Ortrun (Griffith U., Australia). Personal constructs of} second-language teaching: a case study. Babe/ (Victoria, Australia), 23, 3 (1988), 4-9.

This study is part of a team research project on attrition in second-language teaching at the tertiary level, using both quantitiative and qualitative methods of research. The qualitative aspect aims to 
find why students are likely to discontinue (or continue) their L2 learning. Teaching staff were asked at the beginning of the course to describe their personal theories of $\mathrm{L} 2$ teaching by means of a repertory grid. At the end of the course, they were asked to analyse their practice by means of class observation and interaction analysis (using video self-confrontation). Information about students' motivations, expectations and prior experiences with the target language were elicited by means of open-ended questionnaires at the beginning of the course. At the end of the course, students were asked to evaluate their experiences in a structured group discussion.

This paper focuses on the first part, the question of teachers' personal constructs of L2 teaching at tertiary level, and presents a case study of eight academics teaching first-year Chinese, Japanese or Indonesian languages. The methodology was based mainly on Kelly's (1963) Personal Construct Theory and the repertory grid technique based on it. The teachers were asked to think of six language teachers they knew well, two good and two poor, and of themselves $(a)$ at the time of elicitation and $(b)$ in the future. They had to compare three teachers at a time and say how any two were alike and the third was different; they also had to rate all the teachers on a scale for different constructs. The resulting grids were analysed and discussed with the participants. On the basis of both analysis and discussion, a summary of each participant's personal theory of second-language teaching was drafted, as well as group constructs of what constitutes effective teaching. [Table of results.]

\title{
Psychology of language learning
}

\author{
90-13 Anderson-Hsieh, Janet and Koehler, Kenneth (lowa State U.). The \\ effect of foreign accent and speaking rate on native speaker comprehension. \\ Language Learning. (Ann Arbor. Mich), 38, 4 (1988), 561-613.
}

This study investigated the effect of foreign accent and speaking rate on native speaker comprehension. The speakers for the study were three native speakers of Chinese, with TSE (Test of Spoken English) comprehensibility scores of 180,200 , and 260 , and one native speaker of American English. The speakers each read passages at three different speaking rates. The tape-recorded passages were then presented to native speakers of American English who responded to them by taking a listening comphrehension test and rating the speech samples. The results showed that the comprehension scores were significantly higher for the native passages than for the non-native passages and significantly higher at the regular rate than at the fast rate for all speakers. It was also found that the increase in speaking rate from the regular to the fast rate resulted in a greater decrease in comprehension with regard to the most heavily accented speaker as compared with the other speakers, indicating that speaking rate is more critical for the comprehension of heavily accented speech. In addition, the results suggested that prosodic deviance may affect comprehension more adversely than does segmental deviance.

\section{0-14 Collin, Annie. L'acquisition des pronoms, articles et auxiliaires anglais en milieu scolaire: verification de l'hypothèse de Tarone. [The acquisition of English pronouns, articles and auxiliaries in a school setting: verification of Tarone's hypothesis.] Mélanges Pédagogiques (Nancy, France), 1988, 31-47.}

This article reports on a research project whose aim was to test Tarone's hypothesis that during the learning process an $\mathrm{L} 2$ structure first appears in the interlanguage in the most formal style and then shifts along the interlanguage continuum to progressively more colloquial styles. A corpus consisting of the written work produced by three secondary- school learners of English over a one-year period was analysed on the basis of four variables: learners, learning items, styles and time (rapidity and moment of acquisition). The results confirm Tarone's hypothesis, though they also demonstrate considerable individual variation. 
90-15 Cook, Vivian J. (U. of Essex). Language learners' extrapolation of word order in micro-artificial languages. Language Learning (Ann Arbor. Mich), 38, 4 (1988), 497-529.

This article is concerned with the ability of language learners to extrapolate from the word order in one type of phrase to that in another, namely from the order in the verb phrase (VP) to the orders in the prepositional (PP) and noun phrases (NP) and from the verb phrase order plus either the prepositionalphrase order or the noun-phrase order to the other phrase type. Such extrapolation relates both to the implicational universals of possible word orders in language described by Hawkins and to the head parameter of Chomsky's Government/Binding Theory.

This article describes an experiment with eight Micro-Artificial Languages (MALs) that tested the ability of 409 secondary-school children to ex- trapolate in this way. The results showed that most learners (340) were highly consistent in ascribing word order and most (321) succeeded in learning the MALs. Four extrapolation strategies followed by the learners that are not covered by the syntactic analyses mentioned are preferences for (1) postpositions, whatever the VP order; (2) adjectives in the same position as objects in the VP; (3) prepositions the same side as adjectives in the NP and objects in the VP; and (4) adjectives before nouns if the VP order and the NP order are consistent. Further research is needed to see if such extrapolation strategies occur in real learning or if they are an artefact of the MAL approach.

\section{0-16 Corrales, Olga (U. of Costa Rica) and Call, Mary Emily (Montclair State Coll.). At a loss for words: the use of communication strategies to convey lexical meaning. Foreign Language Annals (New York). 22, 3 (1989), 227-40.}

The study of communication strategies can provide insights into the ways in which interlanguage changes and develops as language learners become increasingly proficient in the target language. This article describes an investigation centred on the communication strategies used by two groups (intermediate and advanced) of Spanish-speaking students of English to express lexical meaning. Two different tasks, one consisting of answering structured questions and the other a simulated communication situation, were used to elicit data from the students. Data were collected at two different times, once at the beginning of the term and again five weeks later. Proficiency level, task and time were the independent variables and three types of communciation strategies (transfer, overgenerali- sation, and task-influenced) were the dependent variables. It was found that the unstructured task elicited significantly more transfer strategies from both groups of students, and that there was a significant interaction between time and proficiency level with respect to the use of task-influenced strategies - the advanced group used a greater mean proportion of task-influenced strategies than the intermediate group at Time 1 , while the intermediate group used a greater mean proportion of this type of strategy at Time 2 . A post hoc analysis of these data suggests that students of a language may go through a period of maximum exploitation of task-influenced strategies which peaks and then drops off as they become more proficient in the language.

\section{0-17 Ellis, Rod (Ealing Coll. of Higher Ed.). The role of practice in classroom learning. AlLA Review (Madrid), 5 (1988), 20-39.}

One of the functions of applied linguistics is to submit pedagogical assumptions to close scrutiny. This article uses both the results of empirical SLA research and SLA theoretical perspectives to examine the pedagogic claims that are frequently made for controlled practice. A model of teaching in which practice is seen as determining learning (the "practice-causes-acquisition' model) is simplistic and not tenable. Controlled practice is a form of classroom interaction and, as such, is a varied phenomenon subject to a host of social and personal factors. It is for this reason above any other, that quantitative studies of practice have produced conflicting results.
Frequently, it is acquisition that determines practice, rather than vice-versa. That is, how much of the L2 a learner already knows controls how much practice she gets, as qualitative studies of practice have shown. Frequently the way practice is conducted by the teacher reflects her assessment of the proficiency attained by individual learners. In this way, practice may simply serve to reinforce the learners' and the teacher's preconceptions about who is succeeding and who is not succeeding. That is, a kind of selffulfilling prophecy may be acted out through practice.

Controlled practice is designed to automatise 
items that are already part of the learner's interlanguage; qualitative studies suggest that it does not achieve this. Frequently learners fail to produce correct exemplars of the target structure and the teacher connives at this. Controlled practice may do little more than develop the strategies needed for reproductive competence. Even if controlled practice is credited with causing learning, there are strong theoretical grounds for believing that only some grammatical features (i.e. 'variational' features that are computed simply) can be influenced easily by practice. Controlled practice will only facilitate the acquisition of 'developmental ' features if the necessary processing prerequisites have been established. Controlled practice is a source of 'input'; the learner may select from this input what she is ready and prepared to process, irrespective of what structure is the target of the practice. The real role of controlled practice may be to raise the learner's consciousness about language form. This consciousness may not be convertable into implicit knowledge immediately but may facilitate it in the long term. There may be better ways of raising the learner's consciousness than controlled practice, however. In the case of controlled practice, the old axiom 'practice makes perfect' may not apply to language learning or, at least, not in the way that many teachers and methodologists think it does. Practice may only facilitate acquisition directly if it is communicative, i.e. meaning-focused in nature.

\section{0-18 Gierut, Judith A. (Indiana U.). Comparative research on language learning. Language Learning (Ann Arbor, Mich), 38, 3 (1988), 409-32.}

This paper integrates the research concerns of two language-learning populations, adults acquiring a second language and children learning to correct functional (non-organic) speech sound errors. Phonology was specifically examined with regard to four areas of mutual concern and benefit: (a) characterisation of the sound system, $(b)$ selection of aspects of the target sound system to be taught, (c) projection of learning during instruction, and (d) application of research findings to classroom and clinic. This comparative research indicated that basic theoretical and pedagogical aims overlap for both populations. Also, research on both populations has resulted in similar findings about language, learning, and instruction. Moreover, the study of each population has shown certain advances that may contribute to, and shape the direction of, language learning research for the other population. Integrated research efforts of this type have potential for isolating properties that are necessary and specific to language from those that are unique to acquisition, and further, for differentiating these universal properties from those that are specific to given language-learning populations.

\section{0-19 Harlow, Linda L. (Ohio State U.). The effects of the yellow}

highlighter - second-language learner strategies and their effectiveness: a research update. Canadian Modern Language Review (Toronto), 45, 1 (1989), 91-102.

Learning strategies are 'a set of processes or steps (used by a learner) that can facilitate the acquisition, storage and/or utilisation of information'. This paper reviews research on general learner strategies (note-taking, co-operative learning, metacognitive activities, verbalisation techniques) and on secondlanguage learner strategies (including work on the 'good' language learner). The findings of studies in which achievement on various tasks is correlated with specific learning behaviours are summarised in a reference chart. Some tentative conclusions support the cognitivist view of second-language learning as a dynamic, creative process requiring the active participation of the learner (active mental processing of input). Many entries focus on the importance of functional practice (making opportunities for practicing communication and/or comprehension skills). Teachers are asked to consider a series of questions as to whether their teaching techniques encourage the practice of proven techniques, such as informed guessing: do they allow time for self-monitoring techniques? Do they encourage students in their self-initiated efforts to learn? Do they promote co-operative learning and small-group work?

\section{0-20 Hayes, Elisabeth (Syracuse U.). Hispanic adults and ESL programmes: barriers to participation. TESOL Quarterly (Washington, DC), 23, 1 (1989), 47-63.}

Hispanic adults represent a significant proportion of the low-literate population in the United States and are thus a group of great potential concern to educators. Attempts to increase the English literacy levels of this group are limited by lack of empirical data regarding variables that affect Hispanics' participation in educational programmes. The purpose of the study reported in this article was to gather 
information about barriers to participation in ESL programmes for these adults. Data were obtained from 200 Hispanic ESL students with the Deterrents to Paricipation Scale-Form LLS (adapted from Hayes \& Darkenwald, 1988). Four orthogonal factors were identified through principal components analysis of the data: Self/School Incongruence, Low Self-Confidence, Lack of Access to
Classes, and Situational Constraints. Through disjoint cluster analysis, five types of low-literate Hispanic adults were identified according to their scores on the four deterrent factors. These findings provide information that can be used as the basis for developing strategies and programmes to meet the ESL needs of specific subgroups of the adult Hispanic population.

\section{0-21 Kennedy, Barbara L. (U. of Alabama at Birmingham). Adult versus child L2 acquisition: an information-processing approach. Language Learning (Ann Arbor. Mich), 38, 4 (1988), 477-95.}

This article assumes that adult L2 learners cannot achieve the same degree of proficiency in their L2 that child L2 learners can. An information-processing approach to this phenomenon is presented; the aspects of unitisation, faulty or incomplete declarative knowledge, and limited working memory space are used to account for the deficiencies often found in adult learners' L2 competence. Once L1 procedural-knowledge productions have become unitised, it is difficult to alter them. If an L2 production responds to the same cue as does an $\mathrm{L} 1$ production, interference from the $\mathrm{L} 1$ often occurs. Conscious effort is required to overcome these problems, as well as correct and complete declarative knowledge; however, in an actual communicative situation, conscious effort is focused most often on the semantics of the communication, rather than on the mechanical forms, and the strongest unitised (automatic) productions take over. Moreover, if the learner is able to focus on forms, he/she may not have all of the declarativeknowledge of the L2 he or she needs or enough working memory space to manipulate all that is required. Justification for the application of a cognitive psychology model to L2 language learning is given. In addition, the information-processing model is compared to a model that requires a totally separate language acquisition device to account for the same phenomenon.

\section{0-22 Morgan, James L. and others ( $U$. of Minnesota). Facilitating the acquisition of syntax with cross-sentential cues to phrase structure. Journal of Memory and Language (New York), 28, 3 (1989), 360-74.}

Several previous studies using miniature language methodology have shown that the acquisition of syntax is facilitated by language input that incorporates cues to sentence phrase structure. These studies have examined effects of local cues, such as prosody or function words, which are physically identifiable aspects of input and which directly indicate the phrase bracketing of individual input strings. In the present study, we examine the effects of cross-sentential cues to phrase structure - cues that lack overt manifestations in individual strings, arise solely as consequences of the rule system underlying the input language, and must be extracted from input through comparisons of semantically and syntactically related strings. Gram- mars incorporating rules of pronominalisation and permutation were used to generate input with cross-sentential cues. Subjects exposed to such input were completely successful in learning syntax, whereas subjects exposed to input generated by a simpler grammar (and lacking either local or crosssentential cues) failed to learn complex aspects of syntax. Natural languages regularly include the types of rules that give rise to cross-sentential cues and also regularly possess multiple local cues to phrase structure. These patterns of universality, coupled with the consistent facilitative effects of structural cues on learning, suggest that such cues may constitute a necessary component of language input.

90-23 Neufeld, Gerald G. (U. of Ottawa). Phonological asymmetry in secondlanguage learning and performance. Language Learning (Ann Arbor, Mich), 38, 4 (1988). 531-59.

This paper reports on the results of a study in which adult second-language learners' performance on phonological perception tasks was contrasted with their performance in articulatory production. The project was a continuation of earlier work in which the writer found no evidence for language-learning 
deficits at the level of perception and notable asymmetry between phonological perception and articulatory production in L2. The objectives of the work discussed here were to take a closer look at some of the factors that might account for asymmetry and to see what implications our additional findings might have for the continuing debate about developmentally induced languagelearning disabilities.

\section{0-24 Oxford, Rebecca (Annenberg/CPB Project) and others. Vive la différence? Reflections on sex differences in use of language learning strategies. Foreign Language Annals (New York), 21, 4 (1988), 321-9.}

In a review of some 80 articles, papers and chapters describing language-learning strategy research, only four studies were found which directly examined sex differences in strategy use. In these four, significant sex difference almost always occurred in a single direction, reflecting greater use of languagelearning strategies by females. These studies are described and analysed here. In three of the four, frequency and variety of strategy use were sig- nificantly greater for women. The one training study produced one significant sex difference which favoured men and two which favoured women, but these were in response to training. Sex differences showed women's greater desire for social approval, greater willingness to accept existing norms, and greater verbal ability. More research might show sex differences of varying types favouring each of the sexes.

\section{0-25 Pica, Teresa (U. of Pennsylvania). Morpheme data analysis in second- language acquisition research: renewing an old debate and raising new issues. ITL (Louvain, Belgium), 79/80 (1988), 77-112.}

This article reviews options which confront secondlanguage acquisition researchers in their analysis of a learner's morpheme production. It critically examines several different procedures which can be used to compute production accuracy, particularly when assigning values to morpheme oversuppliance, substitution, and regularisation, and then reviews various ways in which morpheme suppliance scores can be computed within individual linguistic contexts or on overall basis, across a speaker's corpus.

Conversations with 18 native Spanish-speaking adult acquirers of English L2 are used to highlight the often contradictory results obtained when one procedure is chosen over another to quantify the same corpus of morphemes, and to set forth problems which arise when comparisons are made of learners whose morpheme production accuracy has not been computed under the same procedures. It is argued that issues arising from procedural choices in morpheme data analysis are also relevant to research on other dimensions of second-language acquisition.

\section{0-26 Sandra, Dominiek (U. of Antwerp). Is morphology used to encode derivations when learning a foreign language? ITL (Louvain, Belgium), 79/80 (1988), 1-23.}

Derived words suggest a very efficient mnemonic when they have to be learnt as items in a foreign language (FL). They could be remembered by tagging in semantic memory the property that is lexicalised by the stem and storing the particular affix. A learning experiment was designed to find out whether students make spontaneous use of this encoding strategy. The results indicated that subjects' recall performance was better for derived words than underived ones, even when the presence of stems was not pointed out to them by the experimenter. The error data were compatible with the use of the proposed mnemonic. Surprisingly, subjects who were given only native language translations did better on the derivations than those who were provided with additional comment on the morphological structure of these words. This finding proves that the method of giving translations for FL words can be useful and that the memory representations subjects form in such conditions are not necessarily of the paired-associate type. 
90-27 Tierney, Robert J. (Ohio State U.) and others. The effects of reading and writing upon thinking critically. Reading Research Quarterly (Newark. Del), 24, 2 (1989), 134-73.

The major question driving this study was whether writing in combination with reading prompts more critical thinking than reading alone, writing alone, or either activity combined with questions or with a knowledge activation activity. To answer this question, the authors randomly assigned 137 undergraduate students to one of 12 treatment groups involving combinations of the following conditions in relation to one of two topics: (a) an introductory activity (writing a letter to the editor, engaging in a knowledge activation task, or no activity): (b) a reading condition (reading or not reading an editorial passage about the topic); and (c) a question condition (answering or not answering questions related to the topic). Subsequent to these activities, all subjects wrote a letter to the editor (or a second draft if they had already written one) and responded to debriefing questions about the tasks. Analyses were conducted of the subjects' letters and revisions, responses to the questions, and debriefing comments.

Significant differences emerged between students who both wrote and read and students in any of the other treatment groups. For example, an examination of the revisions suggested that students who both wrote and read produced significantly more changes than students who wrote but did not read. And, if thinking critically entails a greater willingness to revise one's position on an issue, then the data from the debriefing comments suggest that reading and writing in combination are more likely to prompt critical thinking than when reading is separated from writing or when reading is combined with knowledge activation or answering questions.

\section{0-28 VanPatten, Bill (U. of Illinois). Can learners attend to form and content while processing input? Hispania (Worcester, MA) , 72, 2 (1989). 409-17.}

Three hypotheses were tested: (a) if learners have difficulty in attending to both content and form, a task involving conscious attention to non-communicative grammatico-morphological forms will reduce comprehension of content; $(b)$ if they concentrate on meaning, a task involving conscious attention to important words will not affect comprehension; and (c) advanced learners will exhibit different performance to beginners.

American learners of Spanish were required to listen to a passage in Spanish, and were set four tasks: to listen (1) for meaning, (2) for meaning plus occurrence of the verb morpheme $-n$, (3) for meaning plus definite article $1 a$, and (4) for meaning plus occurrence of the word inflacion. Results supported the first two hypotheses, but were inconclusive for the third, with task (2) causing particular difficulty. Future research needs to consider whether the processing of syntax operates in the same way as that of morphology, whether comprehension may be distinguished from acquisition during input and the effect of other methodologies.

\section{Research methods}

\section{0-29 van Els, Theo and Wettens, Bert. Foreign language loss research from a European point of view. ITL (Louvain), 83/4 (1989), 19-35.}

The focus here is on non-pathological, intragenerational language loss, i.e. loss of language competence within individuals. There are four main types: (1) loss of L1 in an L1 environment (first language loss by ageing people); (2) loss of L1 in an L2 environment (loss of native languages by immigrants); (3) loss of L2 in an L1 environment (foreign language loss), and (4) loss of L2 in an L2 environment (second language loss by ageing migrants). Very little research has been done, though it could be argued that all research is relevant which concerns the testing of the effects of foreign language teaching programmes some time after completion.
Usually in these cases, however, the researchers are not interested in the phenomenon of loss as such.

Some ongoing research in this area is described, mainly taking place at the University of Nijmegen in the Netherlands: a project on the loss of French by Dutch people, another on the loss of language competencies in ageing people; a third investigates the loss of German, and how far the process of loss is the inverse of the acquisition process.

Research issues outlined include the definition of foreign language loss, the intervening variables and the measurement of loss. In the search for general patterns of loss, a major difficulty is the baseline 
with which to compare the measurements of loss: how to assess the FL competence the subjects once had. It seems likely that the level of this competence is a major factor affecting the degree and rate of loss: at low levels of competence, loss may be total, but once a 'critical threshold' of competence has been reached, attrition is less likely. Findings suggest that there is no loss of global competence; there is loss of grammatical competence but not of phonological discrimination nor of lexical competence.

Intervening variables, external factors which interact with the loss processes, include amount and kind of input, length of period of non-use including incidental contact with the foreign language, and changes to the 'attriter' through his own development.

The measurement of loss may be made either by tests of linguistic competence or by self-assessment by the 'attriter'. In connection with the latter, subjects tend to be rather negative about the effects of non-use on their FL competence. [The whole issue is devoted to language loss.]

\section{Testing}

90-30 Alderson, J. Charles (U. of Lancaster). New procedures for validating proficiency tests of ESP? Theory and practice. Language Testing (London), 5, 2 (1988), 220-32.

This paper reports on work in progress on an international project to revise the English Language Testing Service (ELTS) test, currently jointly produced and administered by the British Council and the University of Cambridge Local Examinations Syndicate. The project is trying out what it believes are somewhat new approaches to the content validation of the revised test, and both the rationale for this and the details of the procedures for test validation are set out here. It remains to be seen, however, whether such procedures will result in improved construct, concurrent or predictive validity.

90-31 Bachman, Lyle F. (U. of Illinois at Urbana Champaign) and others. Task and ability analysis as a basis for examining content and construct comparability in two EFL proficiency test batteries. Language Testing (London), 5, 2 (1988), 128-59.

Using a diagramatic model of Communicative Language Ability (CLA), a comparability study is made of the Cambridge CPE and FCE on the one hand and U.S. Education Testing Service TOEFL, SPEAK and TWE tests on the other. The model identifies three major components : Language Competence, Strategic Competence and Psychomotor Skills and analyses Language Competence further into a hierarchy of other competences.

The comparison is made with regard to a number of test method facets, e.g. rubric, environment, expected response, etc., which also make for variability and the measures are duly examined and analysed. Both groups of tests represent radically different approaches and test formats yet claim to be functionally similar; they are described in detail. The paper, however, focuses on only one test type - the reading and vocabulary subtests for CPE
Paper 1 and TOEFL - and examines them facet by facet, with a view to $(a)$ characterising the facets so that meaningful comparisons can be made across tests, and $(b)$ estimating or inferring the abilities tapped by different parts of the tests. The results are expressed in 15 tables and deal only with the content and requirements of the papers, not actual results or measures of difficulty.

It is concluded that the test method facets and ability components need to be operationally defined more specifically before any firm conclusions can be drawn but they have provided a useful beginning for comparing content. They interact and overlap in critical ways, however, and the nature of the tasks needs clarifying. The larger study of which this is part is still in progress and will look at actual test performance within a revised framework.

90-32 Brown, James Dean (U. of Hawaii at Manoa). Improving ESL placement tests using two perspectives. TESOL Quarterly (Washington, DC), 23, 1 (1989). $65-83$.

ESL placement testing is commonly conducted at the beginning of students' studies to determine which level of study would be most appropriate. However, serious mismatches can occur between
ESL placement results and the actual progress made by students between levels. The present study was conducted at the University of Hawaii to develop a placement test that would match the curriculum for 
ESL reading. The usual placement procedures were conducted $(N=194)$, using a well-established instrument to test reading comprehension. The 61 students who were placed on the author's reading course were then retested using the same instrument at the end of the 15-week term. The results were analysed using classical norm-referenced and criterion-referenced item analyses statistics. When the results of the norm-referenced analyses (item facility and discrimination indexes) were combined with those of the criterion-referenced analyses (particularly the difference index), serious mismatches between the testing procedures and the ESL programme were revealed. The combined information from both sets of analyses was used to revise the placement test and to improve the match between the test and this specific reading programme.

\section{0-33 de Jong, John H. A. L. and Glas, C. A. W. (Nat. Inst. for Educational Measurement (Cito), Arnhem). Validation of listening comprehension tests using item response theory. Language Testing (London), 4, 2 (1987) [publ. 1989]. 170-94.}

This paper presents evidence for the construct validity of foreign language listening comprehension tests obtained from native speaker data and target population data on the tests. Data are analysed using the Rasch model and item parameters estimated using conditional maximum likelihood estimation. A statistical test is used to identify causes for lack of fit of the data with the Rasch model, and an iterative item deletion procedure is proposed to improve Rasch homogeneity of tests. The measure of fit of items in the analysis of item responses from the target population is shown to be associated with native speakers' results on these items. It is suggested that, as the underlying trait of tests for foreign language listening comprehension, literal understanding of aurally perceived language is preferable to interpretative understanding.

\section{0-34 Hahn, Sidney L. (U. of Nebraska) and others. Grading classroom oral} activities: effects on motivation and proficiency. Foreign Language Annals (New York), 22, 3 (1989). 241-52.

The purpose of this pilot study was to gather initial information on the effects of grading on oral production and attitude of high-school students in first-year German classes. The following questions were addressed in the study: Are structured situational practice activities sufficient, or will students who are graded during situational practice activities be better able to communicate orally than students who are not graded? Is grading in the form of points counted in the student's final evaluation a motivator or incentive to work harder during such activities?

Two groups of beginning German students were studied, one graded, one not graded on their oral performance over the first six months of the school term. Each student was then rated in an oral proficiency interview administered by a certified Oral Proficiency Interviewer, and each student completed an attitude survey. Results indicated that there were differences in proficiency as related to grading for individual students, but no significant difference was found between the two groups, nor again when interaction effects of age, ability, achievement, and learning style were considered. Contrasting attitudes toward grading were expressed by the two groups. The non-graded group would like to have been graded; the graded group considered grading stressful and non-productive. The results have interesting implications for teachers and indicate a need for further investigation of the effects of grading with larger numbers than could be used in the pilot study.

90-35 Hamm, Christiane (Queen's U. at Kingston, Ontario). The ACTFL Oral Proficiency Interview in a Canadian context: the French speaking proficiency of two groups of Ontario high-school graduates. Foreign Language Annals (New York), 21, 6 (1988), 561-7.

Ontario high-school students enter universities with a variety of educational backgrounds in French. In order to obtain information about the French language competence of some of these students, a study was conducted at Queen's University in 1987. Its objective was to rate, by means of the ACTFL
Oral Proficiency Interview, the French speaking proficiency of a group of immersion graduates and a group of core programme graduates who had taken a six-week language course in a francophone environment. The data suggest that (a) immersion graduates tend to perform functions well but at the 
expense of accuracy, and $(b)$ students from the core programme, who take a six-week course, show fewer discrepancies in their speaking skills and

obtain ratings only slightly lower than those of immersion graduates.

\section{0-36 Jafarpur, Abdoljavad (Shiraz U., Iran). The short-context technique: an} alternative for testing reading comprehension. Language Testing (London), 4, 2 (1987) [publ. 1989], 195-220.

Traditional reading tests have been subject to mounting criticism of various kinds. This article discusses some of these criticisms and the ways in which an alternative approach - namely, the shortcontext technique-avoids these defects. It then reports on an attempt to construct a short-context test and the examination of its validity. The results show sufficient evidence substantiating the shortcontext test as an authentic measure of reading ability.

\section{0-37 Lynch, Brian (U. of California, Los Angeles) and others. Person} dimensionality in language test validation. Language Testing (London), 5, 2 (1988), 206-19.

In an attempt to extend our knowledge about potential implications of person dimensionality for language test validation, the study reported here was designed: (1) to identify person similarities in a language proficiency testing data set; (2) to attempt to relate such person dimensions to demographic information on the persons so as to provide appropriate labels for the dimensions; and (3) to investigate differential item functioning for the person dimensions identified and labelled. This final focus of the study was intended to reveal whether test items were functioning in an equivalent and valid manner for all person dimensions and, if not, whether there were any discernible patterns of item types that were functioning differentially for particular person dimensions.

\section{0-38 Major, Roy C. (Washington State U.). Measuring pronunciation accuracy using computerised techniques. Language Testing, (London), 4, 2 (1987), 155-69.}

Techniques for measuring pronunciation accuracy have lagged far behind measuring competence in other areas. It is argued that pronunciation is an important aspect of second language proficiency and just as it is important to have reliable measures of competence in such areas as listening comprehension, grammar, reading and writing, so it is important to have reliable measures of pronunciation accuracy. This paper discusses several com- puterised techniques which measure pronunciation accuracy. They have the advantage over other methods because they rigorously control for such factors as sequence effects and length of utterance. These techniques are applicable in a number of areas, including basic research, measuring proficiency gains in students, comparing different methods and measuring comprehensibility and language attitudes.

\section{0-39 Meara, Paul (U. of London) and Buxton, Barbara (Cassio Coll.). An alternative to multiple choice vocabulary tests. Language Testing (London), 4, 2 (1987) [publ. 1989], 142-54.}

This paper reports a preliminary evaluation of the $\mathrm{Y} / \mathrm{N}$ technique for producing tests of vocabulary knowledge. The results obtained suggest advantages over the more traditional multiple choice format for testing vocabulary.

90-40 Perkins, Kyle and Linnville, Steven E. (Southern Illinois U.). A construct definition study of a standardised ESL vocabulary test. Language Testing (London), 4, 2 (1987) [publ. 1989], 125-41.

This paper reports a construct definition study of a standardised English as a second language (ESL) vocabulary test. The test, which contained 20 stimulus-word items and 17 context-word items, was administered to two different samples of ESL students at different proficiency levels and to a 
sample of native speakers of English. The item responses for the 40 items were used as the dependent variable in a stepwise multiple regression, construct specification equation and 12 variables (measures of the stimulus words' and keyed responses' fluency, distribution, abstractness, length, affective impact, and prototypicality) were used as predictors. Only six of the predictors accounted for a significant amount of variance in the dependent variable, and the number and arrangement of significant pre- dictors varied across proficiency strata, indicating the utility of incorporating the examinees' stages of learning into construct validation studies.

Construct definition studies such as this permit the statement of explicit predictions and a means to falsify construct theory, which is a perceived need in educational and psychological measurement. The paper concludes with an agenda for future research based on the results of the present study:

\section{0-41 Valdés, Guadalupe ( $U$. of California at Berkeley). Teaching Spanish to} Hispanic bilinguals: a look at oral proficiency testing and the proficiency movement. Hispania (Worcester, MA), 72, 2 (1989), 392-401.

The proportion of Hispanic bilinguals now receiving Spanish instruction in the USA is large and growing yet the teaching and testing material is based on the $A C T F L$ Proficiency Guidelines produced in the early ' 80 s for anglo-monolinguals learning Spanish. The validity of these Guidelines is questioned as a description of performance levels for Hispanic bilinguals, as is the oral proficiency interview test based on it as a measure of their competence.

Two student types are identified at either extreme of a continuum, one almost monolingual Spanish and the other bilingual with English dominant.
With such students in mind, the Guidelines are analysed into features of dimensions underlying the generic speaking descriptions and it is shown that several predict little about Hispanic bilingual learners and misrepresent their sequence of linguistic growth; but they operate differentially for each type of student. They should therefore not be used for Hispanic bilinguals without adaptation. Examiners must make public how bilingual Hispanics are rated as compared with their non-native counterparts, otherwise a different oral rating scale should be devised.

\section{Curriculum planning}

90-42 Allen, Patrick and others (Ontario Inst. for Studies in Ed.). Analytic and experimential aspects of core French and immersion classrooms. Bulletin of the CAAL (Montreal, Canada), 10, 2 (1988), 59-68.

Although there is no shortage of teaching material based on one or another of the currently popular approaches, systematic studies of classroom treatment are comparatively rare. Within the context of the five-year Development of Bilingual Proficiency project (DBP) at OISE, several studies were undertaken to examine the relationship between instructional practices and the development of proficiency in a second language. During the first two years of the project, a major focus was on the development and validation of a classroom observation instrument designed to capture the essential features of communication in the L2 class- room. This instrument was subsequently used in a process-product study which examined the impact on L2 proficiency of different instructional practices observed in core French classes. Two other studies involved the analysis of various language use and learning activities observed in French immersion classrooms. One conclusion drawn from this research is that the analytic focus and the experimential focus may be complementary, and may provide essential support for one another in the classroom. The aim of the paper is to discuss selected aspects of the DBP project, and to explore the implications for L2 curriculum and materials design.

\section{0-43 Leaver, Betty Lou and Stryker, Stephen B. (Foreign Service Institute, Washington, DC). Content-based instruction for foreign language classrooms. Foreign Language Annals (New York), 22, 3 (1989), 269-75.}

Content-based instruction (CBI) is a communicative approach to language teaching that is growing in popularity in both government and academic foreign language circles. The authors define $\mathrm{CBI}$ as a curriculum that (1) is based on subject matter, (2) utilises authentic materials, (3) promotes the learning of new information, and (4) considers specific students' needs. Examples of CBI programmes are 
provided. The Russian and Spanish CBI programmes at the Foreign Service Institute are discussed in depth. Readers are requested to share their CBI experience with the authors.

90-44 Nunan, David (Macquarie U., Sydney). Toward a collaborative approach to curriculum development: a case study. TESOL Quarterly (Washington, DC), 23, 1 (1989), 9-25.

This article presents a rationale for the development of a collaborative approach between teachers and curriculum specialists to language curriculum design. The adoption of such an approach within the Australian Adult Migrant Education Program (AMEP) is described, as is the National Curriculum Project, set up within the AMEP to realise the ideals of a collaborative approach.

\section{Course/syllabus design}

\section{0-45 Cathcart, Ruth Larimer (Monterey Inst. of International Studies).}

Authentic discourse and the survival English curriculum. TESOL Quarterly

(Washington, DC), 23, 1 (1989), 105-26.

Classroom language models must be based on authentic native-speaker/native-speaker discourse. The argument is supported with a quantitative distributional analysis of the language of one doctor-patient interaction and examples from three others. The topics, utterance functions, and structures are quantified, and their distribution is examined to show that simulated excerpts may serve to mislead students about the nature of everyday interactions. The implications of this study are discussed in terms of a need for collection of more authentic data, distributional analysis of forms and functions of conversation, and the implementation of a 'discourse behaviour' syllabus for survival English, in which syllabus items are determined by the needs of a participant in a given conversation.

\section{0-46 Ullmann, Rebecca (Education Consultant, Toronto). Complementary approaches to second language programme evaluation. Bulletin of the CAAL (Montreal, Canada), 11, 1 (1989), 57-64.}

This paper, based on a study undertaken for a large urban school board, argues that a complementary process-product approach for evaluating secondlanguage programmes provides a more complete understanding of the programme than evaluation which focuses exclusively on outcome measures of second-language proficiency. It describes a complementary approach used to examine a first-year
French pilot programme at the elementary school level and discusses the procedures and results from the classroom observations and student assessments undertaken during this study. The paper concludes with a discussion of insights gained from the study and makes some suggestions for future studies which explore the relationship between secondlanguage programme treatment and outcomes.

\section{Teacher training}

90-47 Boyd, Frances A. (Columbia U., NY). Developing presentation skills: a perspective derived from professional education. English for Specific Purposes (New York), 8, 2 (1989), 195-203.

The curriculum of programmes of instruction for international teaching assistants (ITAs) commonly covers three areas: language, culture, and teaching. This paper focuses on teaching. At Columbia University, a variety of classroom materials have been developed to train ITAs in practical, readily transferable teaching skills. Even more important, our courses are designed to help ITAs develop a professional self-image in their field of expertise, while fostering a deeper understanding of the American educational system and their role in it. This paper attempts to place ITA courses within the context of professional education. It then goes on to explore the implications of this perspective for the curriculum of such courses, particularly in the area of teaching. Finally, the paper offers a sample of 
curriculum materials written from a professional education perspective. These materials are intended to develop teaching or 'presentation' skills, as well as professional attitudes and values.

90-48 Calvé, Pierre (U. of Ottawa). La formation des enseignants en didactique des langues secondes: le reflet d'une discipline en quête d'autonomie. [The training of teachers in second-language didactics: reflection of a discipline in search of antonomy.] Bulletin of the CAAL (Montreal, Canada), 10, 2 (1988), 15-27.

The training programmes of second-language teachers suffer from serious lacunae. This is due to three major factors: the general weakness of teachers' training programmes, the difficulty that secondlanguage didactics experiences, as an autonomous discipline, in being given the place that it deserves among university programmes, and, finally, the need to recognise the particular requirements involved in training teachers in second-language didactics. In this article, the author deals with each of these factors in turn and concludes by insisting on the need to dedicate a complete university programme to training students who intend to make a career of second-language teaching.

90-49 Davies, Catherine E. and others ( $U$. of Florida, Gainesville). Face-to-face with English speakers: an advanced training class for international teaching assistants. English for Specific Purposes (New York), 8, 2 (1989), 139-53.

This paper describes the advanced phase of the University of Florida ITA training programme, which extends students' linguistic and pedagogical training by concentrating on one-to-one and small group interactions with native speakers. Impetus for the advanced training came from awareness that: $(a)$ one semester was not enough time for many of the students to master the requisite linguistic skills for successful teaching; (b) after leaving the course, students often regressed in linguistic skills and evidence indicated that, outside the classroom, they were existing in a non-English-speaking environment; and (c) successful university teaching involves not only lecturing, but also many crucial one-toone interactions. The goals of the advanced course are that students expand their linguistic skills, crosscultural awareness and strategic competence within the university context, and develop a positive attitude towards becoming involved in an Englishspeaking environment. The methodology develops awareness of where students' individual communication processes are likely to violate native speakers' expectations, and strategies to deal with these problem areas. This is achieved by involving students in frequent one-to-one and small-group interactions with native speakers. The interactions are videotaped and subjected to close analysis in order to provide directed feedback. Initially, the conversations are with 'sympathetic' (i.e. crossculturally sophisticated) speakers; however, once the ITAs are trained in self-monitoring, they meet regularly with undergraduates seeking tutoring in the area of the ITA's expertise.

\section{0-50 Douglas, Dan and Myers, Cindy. TAs on TV: demonstrating communication strategies for international teaching assistants. English for Specific Purposes (New York), 8, 2 (1989), 169-79.}

This paper presents a technique for employing videotaped segments of actual classroom performances by US and international teaching assistants (ITAs). This is a method for training ITAs in specific, definable skills in English language, US academic culture and pedagogical performance, while at the same time developing communication strategies for coping with largely undefinable future communicative needs in their work as teaching assistants. After a brief discussion of previous research on lecture comprehension, focusing especially on the effect of discourse markers, a procedure for developing and using the videotaped materials in an ITA training programme is described, followed by a discussion of the evaluation of the materials and suggestions for further research. 
90-51 Freeman, Donald (Sch. for International Training, Brattleboro, VT). Teacher training, development, and decision making: a model of teaching and related strategies for language teacher education. TESOL Quarterly (Washington, DC), 23, 1 (1989), 27-45.

Two major misconceptions which jeopardise the success of language teacher training are (1) that it is generally concerned with the transmission of knowledge (about applied linguistics and language acquisition) and of skills in methodology and related areas, and (2) that transmission of knowledge will lead to effective practice.

What is language teaching? How do people learn to teach? Teaching is described here as a model of four constituents that interact through the teacher's decision-making: knowledge, skills, attitude and awareness. The first two are uncontroversial, and together make up the 'knowledge base' of teaching. The third factor, 'attitude', is the constituent of language teaching which accounts for individual performance; it is defined as 'the stance one adopts towards oneself, the activity of teaching, and the learners with whom one is engaged in the teaching/learning process'. Though usually overlooked, it is a critical variable. The fourth constituent, 'awareness', functions as the unifying superordinate within the model. It is the capacity to recognise and monitor the attention given to something, more encompassing than 'attention" and less focused. It accounts for why teachers grow and change. The final element in the model captures the dynamism of the process, i.e. 'decision-making'.

If the above model is the content of language teacher education, the process by which it is taught to teachers consists of the strategies of training and development. Training is a strategy for direct intervention by the supervisor (or 'collaborator'), focused on specific outcomes. Development adopts a more holistic and integrated approach: it is a stategy of influence and indirect intervention which works on complex aspects of teaching, with the aim of getting the teacher to generate change through increasing or shifting awareness. The supervisor works by triggering the teacher's awareness of what he/she is doing. The changes which result from development are essentially internal. Solutions are generated by the teacher.

\section{Teaching methods}

90-52 Billières, $M$. (U. of Toulouse-Le Mirail). Non verbal, phonétique corrective et didactique des langues. [The non-verbal element, corrective phonetics and language teaching.] Revue de Phonétique Appliquée (Mons, Belgium), 90 (1989), $1-16$.

This paper shows that a teacher correcting phonetics must be sensitive to such non-verbal parameters as proxemics, voice and eye movements. Corrective phonetics is examined in the context of language didactics, and an analysis is provided of the reasons why didactics either ignores the importance of the non-verbal element or deals with it overintellectually.

\section{0-53 Carton, Francis and Duda, Richard. Production orale: comment mettre} en place des stratégies d'enseignement/apprentissage. [Oral expression: how to use teaching/learning strategies.] Mélanges Pédagogiques (Nancy). 1988, 3-13.

In order to devise activities appropriate to the needs of learners, it is necessary to categorise the different types of oral expression according to the objective to be achieved - whether the aim is to practise vocabulary or pronunciation, stress and intonation, a structure or communication skills. The latter may either involve real-life situations, lending themselves to simulations and role-plays or else an exchange of ideas leading to 'authentic' communication, dialogues and discussions between members of the class. Both presuppose specific skills and prior knowledge of the language needed. [Appendix includes sample exercises.] 
90-54 Davis, James N. (Pennsylvania State U.). Distance education and foreign language education: towards a coherent approach. Foreign Language Annals (New York), 21, 6 (1988), 547-50.

Distance education has grown with the availability of new technologies and increasing numbers of nontraditional students. In the process of distance education, the role of the teacher in the learning process and the interaction of teacher and student are radically altered. The teacher is 'dethroned' and the institution, usually via the mass media, takes the responsibility for learning. Two-way communication is mediated by writing, telephone, two-way radio or television phone-in programmes. Immediate access to the teacher is not usually available, and the student is separated from the learning group. The strongest argument for distance education is its potential to provide instruction for people to whom it is otherwise denied (for economic and other considerations), as in developing countries. In countries with powerful education ministries, such as England, there exist government-sponsored integrated distance education systems such as the Open University. In the US, sponsorship is sought from private funding agencies, and a multi-media approach is used.

Problems include encouraging student-teacher and student-student dialogue and learner autonomy. The student population which most needs interaction to support learning (being less academically prepared) is denied that interaction by many programmes, which are inflexible. Physical distance is not normally a consideration so much as 'transactional distance' - the type and amount of separation of the teacher from the learner in the educational process. Perraton, a theorist on distance education, stresses the importance of the relevance of course content, clarity of presentation and motivation of students. The quality of a programme is determined to a large extent by the amount and immediacy of dialogue. These factors are set beside Krashen's insistence on comprehensible input which must be provided by the course of study and on the reception of that input by the student. His proposals for appropriate teaching can be applied to distance education, for example by using at the early stage the Total Physical Response methodology in conjunction with video. At later stages, the need for native-speaking tutors is greater. At more advanced levels, language can be presented in the form of specific content of interest to the participants. This would be particularly suitable for distance learners, who tend to be more instrumentally motivated than more traditional students. Native or near-native speakers could be available by telephone to registered students. Video teleconferencing might be used to facilitate further interaction.

\section{0-55 Elley, Warwick B. (U. of Canterbury, New Zealand). Vocabulary acquisition from listening to stories. Reading Research Quarterly (Newark, Del), 24, 2 (1989), 174-87.}

In two experiments, classroom teachers in New Zealand read stories aloud to elementary school children, and administered pre-tests and post-tests to measure the extent of the new vocabulary the children acquired from the reading. Results showed that oral story reading constitutes a significant source of vocabulary acquisition, whether or not the reading is accompanied by teacher explanation of word meanings. In the first study, seven classes of 7year-olds showed vocabulary gains of 15 per cent from one story, without any teacher explanation. In the second study, after hearing one story, three classes of 8-year-olds who received no teacher explanation showed gains of 15 per cent, and three classes that did receive explanation showed gains of
40 per cent. By contrast, the same groups produced gains of less than half these figures on a second story, with different characteristics. Follow-up tests showed that this incidental vocabulary learning was relatively permanent, and that low-scoring children gained as much as high-scoring children. In addition, the features that best predicted whether a particular word would be learned were frequency of the word in the text, depiction of the word in illustrations, and the amount of redundancy in the surrounding context. The author recommends future studies to investigate further the benefits from stories read aloud, and to clarify the factors that yield differences in children's interest in stories. 
90-56 Flege, James Emil (U. of Alabama at Birmingham). Using visual information to train foreign-language vowel production. Language Learning (Ann Arbor, Mich), 38, 3 (1988), 365-407.

This feasibility study explored the use of visual information for training vowel production in a foreign language (L2). An optoelectronic glossometer was used to measure tongue-palate distances at four locations along the hard palate and to provide visual feedback specifying tongue targets for English /i,r,æ/ and /a/. Evaluations performed during 10 days prior to training showed that the native Spanish subject examined consistently neutralised the tongue position difference between English $/ i /-/ 1 /$ and $/ \mathfrak{x} /-/ a /$. The same thing occurred when she attempted to imitate vowels spoken by an English native speaker. Physiological, acoustic, and perceptual tests showed that the subject produced a difference between $/ \mathrm{i} /-/ \mathrm{I} /$ after only ten minutes of visual articulatory modeling and shaping. A similar improvement was not noted for $\mid x /-/ a /$, perhaps because the difference in pharyngeal width that distinguishes these vowels could not be shown directly using the glossometer. Additional work will be needed to determine whether the $/ \mathrm{i} /-/ \mathrm{r} /$ change was due to the visual feedback and whether greater-and sustained changes in vowel production can be effected using visual feedback if more training is administered.

90-57 Hakansson, Gisela ( $U$. of Lund) and Lindberg, Inger (U. of Stockholm) What's the question? Investigating questions in second-language classrooms. AILA Review (Madrid), 5 (1988), 73-88.

This paper discusses different aspects of teacher questions. The underlying assumption is that a creative production of utterances in the target language is favourable to language acquisition, and that questions which generate such production should be encouraged. A multidimensional model is proposed by means of which such questions can be characterised. The authors intend to use this model in their research on communication in Swedish-asa-second-language classrooms to delve deeper into the role of teacher questions and the correspondence between different types of questions and the responses they give rise to.

\section{0-58 Hauptman, Philip C. and others ( $U$. of Ottawa). Second-language} acquisition through subject-matter learning: a follow-up study at the University of Ottawa. Language Learning (Ann Arbor. Mich), 38, 3 (1988), 433-75.

This article describes a study of second-language (ESL and FSL) acquisition in which Anglophone and Francophone university students took Introduction to Psychology/Introduction à la psychologie in their second language in a special, sheltered class taught by regular psychology professors. The questions serving as a basis for this study are: (1) Did the experimental subjects successfully master the psychology subject matter? (2) Were there measurable improvements in the secondlanguage proficiency of the experimental subjects? (3) Did the self-confidence of the experimental subjects increase as reflected in their self-reported gains in proficiency, second-language use anxiety and intention to use the second language outside the classroom? Results provide an affirmative answer to the first two questions. In addition, comparison with control groups in language and psychology suggest that sheltered classes are at least as effective as traditional psychology and language classes, and sometimes even better. Results did not provide a definitive answer to the third question although experimental subjects consistently perceived improvements in their second-language skills and those in the FSL study showed a decrease in French use anxiety.

\section{0-59 Jenkins, Joseph R. and others ( $U$. of Washington). Two approaches to} vocabulary instruction: the teaching of individual word meanings and practice in deriving word meaning from context. Reading Research Quarterly (Newark, Del), 24, 2 (1989), 215-35.

In this experiment, the researchers used two approaches to vocabulary instruction with 135 fifth- grade students in US classrooms in order to explore the effects of each approach. One strategy empha- 
sised direct teaching of the individual meanings for a set of unfamiliar words. The second strategy emphasised teaching students to derive word meaning from sentence context, rather than teaching specific meanings. Each strategy was implemented with low, medium, and high amounts of practice, allowing comparison across levels of implementation as well as between treatments. Results from post-tests assessing both students' mastery of the specific word meanings taught and their ability to derive meanings from unknown words showed, first, that instruction in individual meanings effectively taught specific word meanings, whereas the training in deriving meaning improved students' ability to derive word meanings. Second, more practice on individual meanings led to higher levels of mastery of the particular words taught. Third, instruction in deriving meaning was effective with medium and high amounts of practice, but not with less practice. The authors compare the two approaches to previous studies of economical ('lean') and more time-consuming ('rich') forms of vocabulary instruction, and suggest the potential of these two approaches for increasing children's vocabulary learning in the classroom.

\section{0-60 LeBlanc, Raymond (U. of Ottawa) and Guberman, Solange (Carleton U.). L'ordinateur dans l'enseignement des langues: un colosse aux pieds d'argile? [The computer in language teaching - a colossus with feet of clay?] Canadian Modern Language Review (Toronto), 45, 1 (1988), 103-18.}

Computers have been around for some 20 years but their potential for assisting the learner is still not fully exploited; but they will never replace the flesh-and-blood teacher. The failure to take advantage of the computer is due partly to inadequacies in the materials available. Nor, in spite of the apparent variety of training courses on offer, does training in the use of computers figure in general teacher-training programmes.
However, computer-assisted language learning is still in its infancy. Recent work in the field accords priority to the computer's particular strength, i.e. the interaction between learner and machine. In spite of current shortcomings, the future looks bright.

\section{0-61 Little, Greta D. and Sanders, Sara L. (U. of South Carolina). Classroom} community: a prerequisite for communication. Foreign Language Annals (New York). 22, 3 (1989), 277-81.

Communication does not actually take place in the classroom unless the language learners are a community. This became clear in the course of participant-observer research in two language classes (French and German) for beginners. Both teachers were good instructors and used similar communicative techniques. In the German class, however, students seemed to enter more fully into class activities, listened to each other's answers and responded to whoever was speaking; they used their store of shared information in their subsequent interactions. The French students, on the other hand, did not focus on the information in the answers and did not become a community. The notion of a supportive community of learners is central to Curran's Community Language Learning approach (though the German class was not following this approach). A warm, non-threatening, non-competitive classroom atmosphere provides an environment conducive to building such a community.

90-62 Martin, Jean-Pol (U. of Eichstätt, RFA). Quand les élèves font la classe. [When the pupils conduct the lesson.] Français dans le Monde (Paris), 224 (1989), $51-5$.

In order to motivate pupils and create an atmosphere conducive to learning, a method is proposed which combines elements of traditional and modern approaches. The lesson is handed over to the pupils who, using the conventional set textbook, delegate tasks, ask their fellows to read, answer questions or do exercises. The teacher remains in the background intervening only when necessary. The pupils need to master 'classroom language' [list given.] Initially progress may be slow, but stronger motivation enables the class to make up any lost ground. Unlike most other ways of encouraging learner autonomy, this approach does not involve the teacher in extra work. 
90-63 Murphy, John M. Listening in a second language: hermeneutics and inner speech. TESL Canada Journal (Montreal), 6, 2 (1989), 27-44.

Although many teachers think of listening as a passive skill, evidence suggests the opposite. A good parallel is hermeneutics, the art of interpretation, according to which listening is a dynamic process dependent on context, speaker interaction, meaning and rule negotiation and creation, and point of view. Inner speech refers to the way people communicate within themselves whereby external messages become internalised within the listener, frequently involving reduction and non-elaboration. A model of listening strategies for academic settings is elaborated for ESL students which emphasises their need to ask questions, summarise, elicit, argue and review in order to make sense of what they are listening to.

90-64 Seidler, Klaus W. (Lahntalschule, Biedenkopf. Hesse). Old wine in new bottles? A video-letter exchange project as a means of organising cross-cultural learning. British Journal of Language Teaching, 27, 1 (1989), 30-5.

A video exchange was set up between pupils in a German school and a school in the USA. A videocorrespondence requires learning how to handle the equipment, edit the recordings, etc., as well as deciding on topics, planning scenarios and coordinating workgroups. Some of the work has to be done outside school hours. Tasks are done on a rota. Gradually, the co-ordinating role of the teacher can be taken over by a co-ordinating group. Sound quality is more important than picture quality, and intervals between correspondence should not be too long (three or four weeks). Pupils enjoyed receiving and making videos, and benefited from working together over a long period on the project. Individual pen-pal correspondences can be set up at the same time, and various kinds of materials exchanged as well.

\section{0-65 Snyder, Helena Romano (Central Bucks High School West, PA) and Colón, Israel (Temple U.). Foreign language acquisition and audio-visual aids. Foreign Language Annals (New York), 21, 4 (1988), 343-8.}

This study examines the ability of audio-visual aids to facilitate second language acquisition. Some 107 high-school students enrolled in Spanish participated in this study. Two groups were formed which covered identical material except that one group was taught with substantially more and varied audio-visual aids than prescribed by the standard curriculum. At the end of seven weeks both groups were tested on the material covered. The audiovisual aids group performed significantly better in vocabulary and listening comprehension but no difference was found in structure.

\section{0-66 Tudor, Ian (Free U., Brussels). The role of L1 stimulus materials in L2 communicative activities. British Journal of Language Teaching, 27, 1 (1989), 41-7.}

Suspicion of translation in language teaching still persists, but at the activation stage of learning it may provide a useful stimulus. Moreover, translation sometimes corresponds to the authentic needs of $\mathrm{L} 2$ learners, particularly in business or professional contexts. The use of $\mathrm{L} 1$ materials forces learners to make greater communicative efforts and provides more explicit awareness of their communicative strategies. L1 materials may be provided by the learners where they correspond to authentic needs, or by the teacher where they may be used as an integral means to achieve the communicative aims of the task. In one such simulation, materials in English and French were used with a group of Belgian learners to resolve a payment dispute between a British and a French firm. The L1 group experienced more communicative stress and were keener to receive correction of their performance. A follow-up/consolidation phase after the task is recommended to replace interlanguage forms. 
90-67 Wagner, Johannes ( $U$. of Odense, Denmark). Innovation in foreign language teaching. AlLA Review (Madrid), 5 (1988), 99-117.

New trends in linguistics and language teaching theory do not automatically lead to innovation in teaching routines. 'Methods' (well-defined patterns of teaching techniques) are distinguished from ' method' (what actually happens in the classroom); the relationship between them is crucially determined by institutional inertia, and teachers' interactional styles and ideologies. Innovation is introduced more often because of practical con- siderations of classroom organisation and structure than because of its intrinsic pedagogical value. Innovation is dependent on psychological change, whereby psychological imperatives conflict with reality and produce 'knots' (cf. Laing). Such knots inhibit change and promote resistance and insecurity, but may respond to therapy. Teacher training has to start from the complex reality of educational institutions.

\section{0-68 Walker, Ann Arnaud. Implementing whole-brain methods for reading instruction. Journal of the Society for Accelerative Learning and Teaching (Des Moines, lowa). 13, 3 (1988), 291-307.}

This paper reports growth in reading comprehension of remedial junior high students, ages 12 to 14 , who entered this project scoring three or more years below grade level. During the school years from 1984 to 1987 , three groups of pupils numbering 119,142 and 129 were given daily instruction for 47 minutes by a two-teacher team. One of the teachers had received formal training in SALT and other integrative methods. Instruction utilised SALT strategies, Neural-Linguistic Programming and other wholistic techniques. Reading comprehension was measured each September and June using the Stanford Achievement Test. There were no control groups. The average grade level growth in each of the three years was more than 200 per cent of the normal rate. Comparison of project and pre-project yearly gains show acceleration rates of 493,336 , and 285 per cent. The greatest growth, both in grade level and in percentage of acceleration, occurred in the first year.

\section{0-69 Woods, Devon. Error correction and the improvement of language form. TESL Canada Journal (Montreal), 6, 2 (1989), 60-72.}

Except for a few memorable instances when students seem to reach a critical readiness to benefit from error correction, the practice of correcting formal errors in the classroom seems to yield nugatory benefits. In the communicative classroom it goes against the grain.

It is difficult in principle to decide what an error is and to treat it consistently but there are ways in which teachers can show a link between formal error and misunderstanding, thus giving a com- municative underlining to the need for correctness and accelerating those phases of heightened awareness when correction will have a beneficial effect. If students can be made to focus on the communicative consequences of formal error and monitor their own performance, continuous and systematic selfcorrection will take place. A variety of strategies for doing this is suggested, including thematic language teaching. 